\title{
EUCLIDES DA CUNHA: UMA GENEALOGIA
}

\author{
Susan A. de Oliveira ${ }^{*}$
}

\begin{abstract}
RESUMO: Este artigo pretende discutir uma das relações estabelecidas entre a figura de Euclides da Cunha e o imaginário moderno nos primórdios do século $X X$, em periodo imediatamente posterior às Guerras de Canudos e do Contestado. Tendo em vista a influência de "Os sertões" sobre os pesquisadores da Guerra do Contestado, busca-se apresentar os termos em que a figura de Euclides da Cunha não é apenas emblemática para a memória da Guerra de Canudos, mas o elemento discursivo de uma genealogia.
\end{abstract}

PALAVRAS-CHAVE: Euclides da Cunha - Imaginário - Contestado

ABSTRACT: This article intends to discuss one of the relationships established between Euclides da Cunha's character and modern imaginary in the beginning of the XX century, in the period after 'Canudos War' and 'Contestado'. Taking into account the influence of 'Os Sertões' over the researchers of the 'Contestado War', one searches to present the terms in which Euclides da Cunha's character is not only significative to the memory of 'Canudos War', but the discursive element of a genealogy.

KEY WORDS: Euclides da Cunha - Imaginary - Contestado

\section{DO INVENTÁRIO DA MODERNIDADE}

A etimologia da palavra inventário, do latim inventàrium (invèntus, inveníre, inventare), mostra que inventar é o mesmo que procurar, encontrar, descobrir. No entanto, na sua transposição jurídica, inventário significa uma herança, um legado: o que é recebido mediante um recurso à lei. Neste último sentido da palavra inventário, se invoca a lei que permite a transmissão de bens acumulados durante uma vida, enquanto no primeiro, exprime-se um ato inaugural de vontade, o princípio, o novo.

A experiência da modernidade no Brasil de Euclides da Cunha combinou o acerto de contas com as origens coloniais e a afirmação do progresso como sentido da história e nexo de um presente que se queria como transição. No alvor do século XX, por mais que fosse apregoada a confiança nas leis da natureza e da racionalidade para os devires da modernidade, o presente como "experiência do transitório" rearticula o passado e transige com a Razão: é o próprio "sentido da hesitação do homem na história" (MATOS, 1995, p. 32).

Em Os Sertões (1902), Euclides da Cunha manifesta essa hesitação enquanto ato de narrar a própria experiência de um verdadeiro transe entre dois mundos que ele via separados e que se uniriam pelo continuum do progresso e do impulso civilizador. Seria tal hesitação reveladora de um "impasse narrativo que vem expressar, no fundo, um impasse

\footnotetext{
* Doutoranda do Curso de Pós-graduação em Literatura, UFSC. susandeoliveira@hotmail.com.
} 
propriamente histórico" (HARDMAN, 1992, p. 70). As imagens elaboradas pelo autor, como a dos insulamentos e da terra ignota, serviam para narrar o desconhecido, mas também para disciplinar o desconhecimento. Especulativamente, ou ao modo dos geógrafos kantianos da chamada escola alemã, Euclides utiliza-se do apriorismo e separa a terra e o homem. Melhor dizendo, ele cria a estrutura para destacar as imagens que são produzidas no discurso e não as que lhe servem de referente. Assim, alguns recursos de linguagem tornam visível também um impasse epistemológico. Afirma Luiz Costa Lima, sobre a expressão terra ignota:

Contra o propósito de Euclides, é impossível confundi-la com o não conhecido, porque, se fosse apenas desconhecida, a ciência estaria pronta para possuí-la. Mas, sendo terra em que a vida ainda se forja, o narrador precisa de imagens para que, de sua combinação com a hipótese dos cientistas, surja o especulativo. A especulação é produzida pela inter-relação da máquina da mímesis com a disposição crítica fundamental. (LIMA, 1997, p. 171)

A episteme, que rege a modernidade e inaugura o século XX, se constituiu sob os efeitos das imagens: exposições universais, fotografia, imprensa, mapas. A modernidade, no início do século XX, esteve tomada pelos signos do visível, mas, longe de produzir somente evidências, a visão "leva-nos tanto a um fenômeno da ótica física ou biológica como a uma faculdade alucinatória" (DUBOIS, 1995, p. 23). As passagens de Os Sertões fazem da própria escrita um evento das cisões que a modernidade produz e mostram a projeção das imagens do arcaico nas estruturas do moderno, fazendo aparecer a atordoante visão do caos como sombra do progresso.

Assim, inevitavelmente, as potencialidades advindas da escrita de Os Sertões ainda colocam desafios, inclusive da ordem da complexidade do testemunho e das etnografias, pois enquanto carrega todo o peso da memória da Guerra de Canudos (1896-1897), Os Sertões serve de paradigma para a intelectualidade urbana por se constituir como um documento das visões e das projeções do imaginário da modernidade. Angel Rama analisa que

Em Euclides da Cunha ambos os planos ficam separados: ele contempla seres humanos e uma história alucinante, tudo produto de uma cultura que o fascina, mas fala de fora, sem perceber e sem se interessar pelo fato de que esta cultura também deve, forçosamente, gerar um modo literário, uma singularidade narrativa. Não nota que ela não se limita a oferecer ao estrangeiro, procedente de uma outra estrutura cultural, um repertório de objetos mais ou menos exóticos, mas sim um sistema de valores onde estão implicados também os literários. (RAMA, 1978, p. 80-81)

O contato entre a cultura letrada e a cultura sertaneja, que perpassa a narrativa euclidiana, se estabelece através de uma linguagem íngreme conduzida pela sua escrita disciplinada e oscilante, uma depurada arte retórica para traduzir o trágico. Assim, a escrita euclidiana põe em ação a máquina da mímesis que engendra a sua própria hybris da qual provém a idéia de civilização, mas que se enclausura ofuscada e confundida pelas visões de mundo míticas e sincréticas.

Segundo Nietzsche (s.d., p. 49), hybris é uma "palavra perigosa" - a qual, adverte o 
filósofo, nenhum seguidor de Heráclito deveria esquecer -, e é também um termo importante na sua filosofia, pois nela o termo atinge uma significação tal que aglutina elementos de sua crítica ao racionalismo iluminista, do qual o positivismo é portador. Em síntese, o perigo da palavra hybris reside, pois, na confiança excessiva e cega em todo o progresso.

Diz Nietzsche:

todo o nosso ser moderno, enquanto não é fraqueza, mas poder e consciência de poder apresentam-se como pura hybris e impiedade: pois precisamente as coisas opostas às que hoje veneramos tiveram durante muito tempo a consciência do seu lado, e Deus como seu guardião. Hybris é hoje nossa atitude para com a natureza, nossa violentação da natureza com ajuda das máquinas e da tão irrefletida inventividade dos engenheiros e técnicos; hybris é nossa atitude para com Deus, quero dizer, para com uma presumível aranha de propósito e moralidade por trás da grande tela e teia de causalidade - (...) -; hybris é nossa atitude para com nós mesmos, pois fazemos conosco experimentos que não nos permitiríamos fazer com nenhum animal e curiosos viviseccionamos nossa alma: que importa ainda a "salvação" da nossa alma! (id., 2004, p. 102-103)

O que diz Nietzsche toca os pressupostos da subjetividade moderna - e a orientação do posicionamento do sujeito frente à história -, da qual derivam os desdobramentos do racionalismo, este último apregoado, em grande parte, pelas doutrinas positivistas que participaram da formação da intelectualidade brasileira na Primeira República e, conseqüentemente, participaram da formação política e histórica do Brasil, no sentido de que é com essa intelectualidade positivista que surgem mais amiúde os discursos que pretendem inventar o Brasil.

No Brasil, como em toda a América Latina, nos primórdios do século XX, vive-se o afã modernizador, sentido de forma brutal pelas comunidades sertanejas e indígenas, e pelas multidões de excluídos. Viver à margem do letramento tem sido, desde então, para as populações nativas e subalternizadas da América Latina, um dos seus mais importantes enfrentamentos com a modernidade e, nas guerras e lutas sociais que travam, tais populações são, ainda, mais uma vez, marginalizadas pela absoluta impossibilidade de realizar os seus próprios registros escritos. Mesmo que, não obstante, tais registros existam, estes não compõem a sua memória e sim, como bem colocou Angel Rama, tais registros foram, em sua grande maioria, feitos por membros do exército ou realizados sob a sua guarda. Observa Rama que na América Latina coube ao exército aplicar as ações repressoras das quais dependia o modelo modernizador, "ya que él implicaba una reestructuración económica y social que castigaría ingentes poblaciones rurales, forzándolas a una rebelión desesperada” (RAMA, 1985a, p. 350).

Paradoxalmente, à maneira do exército, mas também contra ele, a intelectualidade urbana foi quem produziu os significados e a memória histórica ao mesmo tempo em que, com essa produção simbólica, gerou a sua própria autoridade. Para Rama (1985a), o tema da tragédia de Canudos ocupa um lugar de destaque no plano simbólico e nos diz coisas importantes sobre a América Latina e seus intelectuais. Isso significa que, além do enfrentamento entre projetos sociais e entre culturas diferentes, dá-se um outro tipo de enfrentamento político e cultural pela prevalência das interpretações e representações, geralmente as escritas sobre as orais, as dos vencedores sobre as dos vencidos. Assim, 
Angel Rama (id., p. 349), coerentemente, propõe uma leitura ampliada para a tragédia de Canudos, enquanto tema de grande interesse na América Latina, mas que está, para além da própria história de Canudos, disperso em sua significação ideológica.

O contexto simbólico e ideológico da Guerra de Canudos atinge uma intensa reprodutibilidade de imagens relacionadas às múltiplas interpretações, o que o faz constituir-se como um campo intertextual de referências recíprocas. Tal campo é protagonizado pelo clássico Os Sertões, juntamente com os artigos de Euclides da Cunha sobre a Guerra, suas cartas e sua caderneta de campo, e desdobra-se na filmografia, na literatura de cordel, no teatro, alcançando outros níveis de intertextualidade como a existente entre Euclides e Vargas Llosa em La guerra del fin del mundo (1973), de grande repercussão na crítica literária, e a também conhecida mas ainda pouco explorada relação entre Euclides e o argentino Domingo Sarmiento, especialmente em sua obra visionária Facundo (1845) (GÁRATE, 2001).

Essa é uma das perspectivas pela qual a Guerra de Canudos e a sua narrativa adquirem uma marca genealógica. Michel Foucault (1986, p. 21-23) escreveu, a respeito da genealogia, que esta serve para conjurar a quimera da origem. A genealogia como proveniência (Herkunft), segundo ele, "mostra a heterogeneidade do que se imaginava em conformidade consigo mesmo" e, em fragmentos "restabelece os diversos sistemas de submissão: não a potência antecipadora de um sentido, mas o jogo casual das dominações." A genealogia funciona como uma espécie de assalto à Razão permitindo a existência de saberes e discursividades locais que funcionam por analogias e que se desprendem do todo unitário.

Assim, a partir das interpretações de uma outra guerra, a Guerra do Contestado (1912-1916), observa-se que as discursividades locais surgem com certas marcas genealógicas, como ressonâncias da escrita d'Os sertões. A escrita é um arquivo de semelhanças, diz Walter Benjamin (1985, p. 112). Segundo ele, o atributo mimético - e ao mesmo tempo histórico -, da linguagem faz com que as coisas nela se encontrem e se relacionem. De certo modo, é a partir de uma espécie de gramática da guerra de Canudos que se coloca a questão de que uma grande narrativa como Os Sertões se transformou em um poderoso dispositivo de saber.

A Guerra do Contestado, à semelhança da Guerra de Canudos, também se constitui como um sistema de escrita (SAID, 1986), aparentemente separado e unitário, cujo corpus é composto por narrativas historiográficas e ficcionais, intensa reprodução imagética, filmografia, teatro, eventos comemorativos, romarias e festividades populares. Todavia, nesse campo discursivo e semiótico é inevitável reconhecer que certas imagens e textos, longe de serem símbolos de um acontecimento específico, emblemas de uma origem, são o modus operandi de um imaginário do sertão estruturado pelo pensamento euclidiano. Tal imaginário compôs a missão assumida por grande parte da intelectualidade brasileira - e mimetizada por muitos estudiosos da Guerra do Contestado -, missão esta que seria a de cartografar as fronteiras entre a eugenia e a mestiçagem, entre a civilização e a barbárie, entre o sertão e as cidades e, por fim, traçar os percursos da modernidade.

Dos bandeirantes aos engenheiros elaboram-se as diretrizes da civilização e a erosão das fronteiras naturais e culturais. As metáforas do progresso retiram da produção de ruínas a sua significação (CUNHA, 1995, p. 553). A fusão da cartografia e da poética das ruínas anima o imaginário modernista. 


\section{A "FALTA" DE EUCLIDES}

Enunciar a "falta" de Euclides da Cunha tem como finalidade expressar uma idéia recorrente em grande parte das narrativas sobre a Guerra do Contestado. Para grande parte dos estudiosos do Contestado retratar a Guerra significaria realizar uma tarefa semelhante à de Euclides da Cunha. Oswaldo Rodrigues Cabral coloca os termos em que se expressa essa falta reclamada por tantos outros autores que invocaram a semelhança entre Canudos e Contestado. Segundo Cabral:

Canudos tivera o seu Euclides da Cunha; os observadores do Contestado, se não quiseram imitá-lo, pensaram em seguir as pegadas do mestre que alcançara a imortalidade com a sua obra imperecível. Não admitiram, ou não tiveram a preocupação de procurar a intercorrência de outros fatores, na gênese da luta, que não o religioso. (id., 1979, p. 5)

De todo modo, procurou-se desde sempre colocar a correspondência entre duas Guerras emblemáticas no Brasil. Principalmente, através da interpretação sociológica destes movimentos visando o seu conteúdo religioso, destacou-se entre os sociólogos a discussão sobre o caráter messiânico dos movimentos do Contestado, de João Maria, e de Canudos, de Antonio Conselheiro.

Oswaldo Rodrigues Cabral, precursor dos estudos antropológicos em Santa Catarina e um dos principais intérpretes da Guerra do Contestado, pretendia estabelecer um diferencial de análise frente a outros estudiosos do tema, principalmente opondo-se a Aujor Ávila da Luz, contra o qual travou uma disputa interpretativa sobre a Guerra do Contestado bastante acirrada entre as décadas de 1950 e 1960. Para Cabral, Os Sertões marca um viés de interpretação e de influência, mas o autor procura colocar-se a certa distância crítica do feito de Euclides. Alertara Cabral que

É óbvio, todavia, que a literatura escrita à época não é destituída de valor. Os estudiosos dos assuntos militares e políticos encontrarão nela valioso e copioso material para estudo e meditação. Mas é preciso que se previnam de que tudo foi visto e observado através das lentes escuras de um preconceito - o de fundo religioso. (ibid., p. 5)

Em relação à obra de Ávila da Luz, havia também a influência do preconceito racial além do religioso. Ele adotava, além das teorias raciais, as teorias psiquiátricas sobre as patologias sociais. Ávila da Luz, compôs a sua obra Os fanáticos em 1951, com a mesma estrutura d'Os Sertões, começando pelos aspectos naturais e só depois, analisando as questões sociais e, além disso, ele dialogava explicitamente com os argumentos de Euclides:

Euclides da Cunha, em Os Sertões, já havia notado a sua formidável influência na criação do Canudos do Conselheiro; entretanto, o Conselheiro, vítima de sua paranóia, ainda podia ser considerado o fator principal de Canudos, não fosse a penetração de Euclides da Cunha que viu, no fundo da alma coletiva, as condições extraordinariamente favoráveis para a eclosão daquele fanatismo. (ÁVILA da LUZ, 1999, p. 148) 
Mas, não obstante, houvesse já a advertência de Cabral para os perigos da influência dos preconceitos, e as diferenças entre os dois movimentos fossem também destacadas por ele e também por outros, a comparação entre Canudos e Contestado continuava através da leitura d'Os Sertões. A falta de Euclides da Cunha continuava a ser reiterada. Há inúmeras razões para que as "leituras" da Guerra do Contestado, especialmente até a década de 80, tivessem sido propostas a partir da comparação com Canudos, mas inevitavelmente, é preciso considerar que a recorrente comparação entre Canudos e Contestado surge, em primeiro lugar, do extraordinário valor documental dado ao testemunho de um letrado, ou seja, da crença em uma experiência de escrita fundacional, na existência de um inventário que permita traduzir a missão da modernidade e exorcizar os seus fantasmas:

A chamada Guerra do Contestado foi um dos episódios mais sangrentos de nossa história. Uma saga à altura do grande massacre de Canudos, lá nos sertões do Vaza Barris. Mas que não teve, a descrevê-la, o talento de um Euclides da Cunha. (DERENGOSKI, 1986, p. 11)

No entanto, para além do que está posto retrospectivamente, a reclamada "falta de Euclides" revela a persistência no imaginário de uma visão do sertão em que predominam retratos de natureza morta, cenários de selvageria e povos embrutecidos.

O território do Contestado entra no projeto de modernidade sem fronteiras definidas e, como parte do deserto a ser vencido, integra-se ao itinerário da implantação das ferrovias pelo grupo Farquhar, que deixa miséria e revolta pelos sertões. Itinerário em que encontramos as marcas de Euclides da Cunha. Encontramos Euclides no Contestado, não pela ausência do testemunho de um letrado, não para resgatar o passado e revisitar Canudos, mas pela geografia imaginada da modernidade que colocara Euclides, o grande cartógrafo do sertão - entusiasta do desenvolvimentismo do Barão de Rio Branco -, e o Grupo Farquhar no mesmo percurso: estradas de ferro e vapor, migrações em massa, mestiçagem, ordem e progresso. Lê-se sob a "falta" não a ausência, mas a cartografia do sertão - projeto pessoal de Euclides - como inacabada, aprofundando-se ainda mais a idéia de que a modernidade é sempre um projeto incompleto e inconcluso, sintomático do pensar iluminista.

A "falta de Euclides" também ressalta a idéia de missão do intelectual, de que é preciso cartografar as ruínas, narrar as tragédias modernas ao mesmo tempo em que se projetam os desenhos de uma nação. Nesse sentido, estou tratando da condição ambígua da cartografia, como obra da cidade letrada. A cidade letrada, tal como a concebeu Ángel Rama, é a expressão que conota toda a produção simbólica, ideológica, normativa e escritural, incluindo os seus produtores e atores, destinada a reger a subordinação à forma urbana e à norma letrada de construção da modernidade. Através de dois discursos, em primeiro lugar o da escritura (discurso ordenado pela língua) e, em segundo, o do desenho gráfico (mapas e planos), sendo que este último "superava as virtudes do primeiro, porque era capaz de eludir o plurisemantismo da palavra", observa-se que a cidade letrada teria mantido a "ordem prioritária dos signos" numa realidade já absorvida pelos signos da modernidade. O efeito complementar dos dois discursos criaria, por um lado, a idéia de uma realidade que deveria ser vista como que desterritorializada na sua universalidade e, por outro, a ilusão de uma realidade emancipatória nas desterritorializações que provocava 
(RAMA, 1985b, p. 30-42).

Segundo Rama, a ordenação do espaço, as suas hierarquias sociais, a sua lógica distributiva, a racionalidade pela qual o modelo cultural hegemônico da modernidade se configura é obra da cidade letrada, e podemos lê-la nos mapas. Mas podemos lê-los (os mapas) também como necessidade de simbolização de uma imagem mental, como tradução em signo de uma existência planejada, como uma projeção do futuro, um sonho cartesiano do cartógrafo que se revela ao mundo como um diagrama gráfico (ibid., p. 26-28).

A duplicidade elocutória que Rama percebia nos mapas, de serem, ao mesmo tempo, a representação do concreto e do sonhado, a representação de alguma coisa que lhes é exterior e a si mesmos demonstra, de certo modo, a complexidade da leitura e da ambição cartográfica, expressão da visão moderna. Assim, Euclides da Cunha (1995, p. 548), entusiasmado com "o significado mais progressista e mais nobre da viação moderna", quer dizer, com "o valor da locomotiva no desvendar, extrair, capitalizar, multiplicar, expandir e transformar riquezas", pensava ser a implantação das estradas de ferro o processo potencialmente civilizador, capaz de incluir as populações sertanejas no destino de progresso da nação. Euclides da Cunha, em um dos ensaios de $\grave{A}$ margem da geografia, escreveu sobre a necessidade de incorporar ao projeto de modernidade "as gens obscuras do sertão", e prossegue:

Mas, para isto é possível que não seja o processo mais civilizado o processo mais civilizador. As sociedades, que são fenômenos naturais, não dão saltos. As gentes sertanejas, com seus hábitos antigos, vezadas aos remansos de uma vida primitiva, não poderão, certo, ascender de chofre ao nosso meio. (...) A locomotiva veloz, golfando-lhes de improviso em pleno seio todas as exigências de um estado social superior, não as atrairá. Talvez as repila, ou as deixe indiferentes, ou, o que é mais sério, as deixe suplantadas. Não precisamos exemplificar. (CUNHA, 1995, p. 547)

O projeto de Euclides cartógrafo visava a conclusão da sua obra sobre a Amazônia que era, até então, apenas os ensaios reunidos em Contrastes e Confrontos (1907) e no livro inacabado À margem da história (1909). Pretendia ele, também, mapear a região do centrooeste que era parte do projeto ferroviário a ser encampado pelo Grupo Farquhar por concessão do governo brasileiro. Não pôde fazê-lo. Depois que Euclides morreu, em 1909, o grupo Farquhar - de procedência norte-americana e em atividade no Brasil desde 1904 prosseguiu a escavar o sertão e soterrar os espaços "naturais", esses lugares à margem da história, metáfora do Brasil que resiste ao processo civilizador.

Todas as grandes estradas, no evitarem os empeços que se lhes antolham transpondo as depressões e iludindo os maiores cortes com os mais primitivos recursos que lhes facultem um rápido estiramento dos trilhos, erigem-se nos primeiros tempos como verdadeiros caminhos de guerra contra o deserto, imperfeitos, selvagens. (...) Depois evolvem; e crescem, aperfeiçoando os elementos da sua estrutura complexa, como se fossem enormes organismos vivos transfigurando-se com a própria vida e progresso que despertam. (CUNHA 1995, p. 314-315)

A modernização do sertão como "guerra contra o deserto" foi, no mapa imaginário 
de Euclides, tragicamente, uma metáfora antecipatória da guerra efetiva, iniciada pela chegada ao sertão do sul do Brasil do Grupo Farquhar e dos trilhos que, sob o seu comando, foram totalmente implantados no território do Contestado em 1910.

\section{REFERÊNCIAS}

ÁVILA da LUZ, Aujor. Os Fanáticos. 2a edição. Florianópolis: Ed. UFSC, 1999 BENJAMIN, Walter. Magia e técnica, arte e política. São Paulo: Brasiliense, 1985.

CABRAL, Oswaldo Rodrigues. A campanha do Contestado. $2^{\mathrm{a}}$ edição. Florianópolis: Lunardelli, 1979.

CUNHA, Euclides da. Obra completa. Vol.1 e 2. Rio de Janeiro: Nova Aguilar, 1995.

DERENGOSKI, P. R. O desmoronamento do mundo jagunço. Florianópolis: Fundação Catarinense de Cultura, 1986.

DUBOIS, Claude-Gilbert. O imaginário da renascença. Brasília: Editora da Universidade de Brasília, 1995.

FOUCAULT, Michel. Em defesa da sociedade. São Paulo: Martins Fontes, 2002.

GÁRATE, Miriam V. Civilização e barbárie n'Os Sertões. Campinas: Mercado das Letras, 2001.

HARDMAN, Francisco Foot. Antigos mapas gizados à ventura. Remate de Males, Revista do Instituto de Estudos da Linguagem da Unicamp, Campinas, número 12, p.65-78, 1992.

LIMA, Luiz Costa. Terra Ignota. A construção de Os Sertões. Rio de Janeiro: Civilização Brasileira, 1997.

MATOS, Olgária C. F. Os arcanos do inteiramente outro. $2^{\mathrm{a}}$ edição. São Paulo: Brasiliense, 1995.

NIETZSCHE, Friedrich. A filosofia na idade trágica dos gregos. Lisboa: Edições 70, s/d. Genealogia da moral. São Paulo: Companhia das letras, 2004.

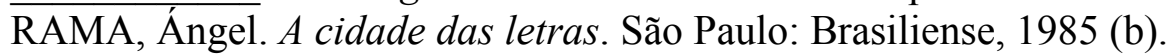

Os primeiros contos de dez mestres da narrativa latino-americana. São

Paulo: Paz e Terra, 1978.

La critica de la cultura en América Latina. Caracas: Biblioteca Ayacucho,

1985 (a).

SAID, Edward. Orientalismo. São Paulo: Cia das Letras, 1986.

Cultura e imperialismo. São Paulo: Cia das Letras, 1995.

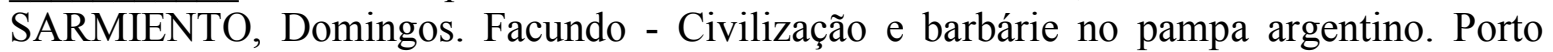
Alegre: Ed. Universidade UFRGS/ EDIPUCRS, 1996.

VARGAS LLOSA, Mario. A Guerra do fim do mundo. $9^{a}$ edição. Rio de Janeiro: Francisco Alves Editora, 1981. 